\title{
Structural and Thermal Behaviour of the Pyrrolidinium Based Ionic Liquid Crystals [C10mpyr]Br and [C12mpyr]Br
}

\begin{tabular}{|r|l|}
\hline Journal: & Zeitschrift für Anorganische und Allgemeine Chemie \\
\hline Manuscript ID: & zaac. 200900216 \\
\hline Wiley - Manuscript type: & Article \\
\hline $\begin{array}{r}\text { Date Submitted by the } \\
\text { Author: }\end{array}$ & 14 -Apr-2009 \\
\hline $\begin{array}{r}\text { Complete List of Authors: } \\
\text { Keywords: }\end{array}$ & $\begin{array}{l}\text { Mudring, Anja-Verena; Ruhr-Universitaet Bochum, Anorganische } \\
\text { Chemie I }\end{array}$ \\
\hline &
\end{tabular}

\section{scholaroNE \\ Manuscript Central}




\title{
Structural and Thermal Behaviour of the Pyrrolidinium Based Ionic Liquid Crystals $\left[\mathrm{C}_{10} \mathrm{mpyr}\right] \mathrm{Br}$ and $\left[\mathrm{C}_{12} \mathrm{mpyr}\right] \mathrm{Br}$
}

\author{
Anna Getsis and Anja-Verena Mudring* \\ Ruhr-Universität Bochum, Anorganische Chemie \\ In memoriam Prof. Dr. Dr. h.c. Joachim Strähle
}

\author{
*Prof. Dr. Anja-Verena Mudring, FRSC \\ Anorganische Chemie I \\ Ruhr-Universität Bochum \\ Universitätsstrasse 150 \\ D-44801 Bochum \\ Fax: (49) 23427408 \\ E-Mail: anja.mudring@rub.de \\ http://www.anjamudring.de
}




\begin{abstract}
The ionic liquid crystals N-decyl-N-methylpyrrolidinium bromide, $\left[\mathrm{C}_{10} \mathrm{mpyr}\right] \mathrm{Br}$, and $\mathrm{N}$-dodecyl-N-methylpyrrolidinium bromide, $\left[\mathrm{C}_{12} \mathrm{mpyr}\right] \mathrm{Br}$ have been synthesized. X-ray diffraction single crystal structure analyses ([C $\left.\mathrm{C}_{10} \mathrm{mpyr}\right] \mathrm{Br}$ : monoclinic, $P 2_{1} / n$, no. $14, Z=12$, Pearson code mP588, $a=$ 19.446(2) $\AA, b=7.0659(5) \AA, c=36.844(4) \AA, \beta=90.63(1)^{\circ}, 4317$ unique reflections with $\mathrm{I}_{\mathrm{o}}>2 \sigma\left(\mathrm{I}_{\mathrm{o}}\right), \mathrm{R}_{1}=0.0372, \mathrm{wR}_{2}=0.0822, \mathrm{GooF}=0.897, \mathrm{~T}=$ 298(2) K; [ $\left.\mathrm{C}_{12} \mathrm{mpyr}\right] \mathrm{Br}$ : monoclinic, $P 2_{1} / n$, no. $14, Z=12$, Pearson code mP660, $a=20.457(8) \AA, b=7.0796(16) \AA, c=39.335(14) \AA, \beta=96.96(3)^{\circ}, 4158$ unique reflections with $\mathrm{I}_{\mathrm{o}}>2 \sigma\left(\mathrm{I}_{\mathrm{o}}\right), \mathrm{R}_{1}=0.0431, \mathrm{wR}_{2}=0.0753$, GooF $=0.823, \mathrm{~T}$ $=298(2) \mathrm{K})]$ reveals for both compounds a layer structure. Sheets composed of hydrophilic structure regions built by positively charged pyrrolidinium head groups and bromide anions alternate with hydrophobic areas formed by interdigitated long alkyl chains belonging to pyrrolidinium cations with opposite orientation. Thermal analyses together with polarizing optical microscopy show that both compounds are thermotropic liquid crystals adopting smectic mesophases. For $\left[\mathrm{C}_{10} \mathrm{mpyr}\right] \mathrm{Br}$ the solidification temperature is dramatically depressed and the liquid crystalline state is preserved metastably at room temperature and well below $\left(\sim-80^{\circ} \mathrm{C}\right)$. In contrast $\left[\mathrm{C}_{12} \mathrm{mpyr}\right] \mathrm{Br}$ solidifies around room temperature $\left(\sim 23^{\circ} \mathrm{C}\right)$.
\end{abstract}


Keywords: Ionic Liquids; Ionic Liquid Crystals; Liquid Crystals 


\section{Introduction}

The liquid crystalline state of matter shows characteristics which are in between that of a three-dimensionally ordered crystalline solid and an isotropic liquid where the constituents are distributed randomly through space. ${ }^{1}$ The liquid crystalline state is often addressed as the "fourth state of matter". ${ }^{2}$ Generally, in the liquid crystalline state a random distribution of particles - like in a classical liquid - is observed at least in one direction of space whereas in another direction a substantially higher degree of ordering is adopted which comes close to the periodicity of crystalline material. Typically, many of the physicochemical properties of liquid crystals (LCs) such as refractive index, electric permittivity, magnetic susceptibility, and mechanical properties like viscosities highly depend on the direction in which these properties are measured. Molecular liquid crystalline materials have found widespread application in display technology in laptops, mobile phones, or flat screen television sets. ${ }^{3}$

Whilst most known thermotropic liquid crystals are neutral molecular organic compounds of strong anisotropic shape, ionic liquid crystals (ILCs) are constituted by anions and cations. Mesophasic behaviour can be introduced into such an ionic material via either one of the ions. It is known that 1-alkyl-3methylimidazolium salts with long alkyl chains (generally with twelve and more carbon atoms in the side chain) adopt mesophases ${ }^{4}$ and the mesophase stability rapidly increases with increase in the alkyl chain length. The driving forces for the formation of mesophases in such ILCs are hydrophobic interactions of alkyl groups and ionic, dipole-dipole, cation $-\pi$ interactions as well as $\pi-\pi$ stacking of the commonly used aromatic core groups. It has been realized that ILCs show unique characteristics that cannot be observed in conventional molecular LCs. For example ILCs show a strong tendency for spontaneous homeotropic alignment. ${ }^{5}$ In ILCs a tetragonal smectic phase $S_{\mathrm{T}}$ was observed for the first 
time. ${ }^{6}$ Applications of ionic liquid crystals include today the use as ionconductive materials, organized reaction media or self-assembled nanostructured materials. ${ }^{7}$ As the cations have amphiphilic character lyotropic mesophases can be expected to exist in combination with various solvents. ${ }^{8}$

For a long time the exploration of thermotropic ionic liquid crystals with $N, N$-dialkylpyrrolidinium cations have been neglected. However, such compounds are of potential interest as the pyrrolidinium cations exhibits a high electrochemical stability. Thus, the compounds might be of relevance in electrochemistry as ion-conductive materials but offer also the possibility for the synthetic chemist to stabilize metals in uncommonly high or low oxidation states. Here we present the first studies single crystal structures of long chain pyrrolidinium based thermotropic liquid crystals along with their chemical and physicochemical properties.

\section{Experimental Section}

All synthesis and sample handling were carried out under standard Schlenk and Argon-glove box techniques. All solvents were dried using standard procedures.

\section{Synthesis.}

1-Methyl-3-n-alkylpyrrolidinium bromide, $\left[\mathrm{C}_{n} \mathrm{mpyr}\right] \mathrm{Br}, \mathrm{n}=10,12$. In a typical reaction 0.1 mol N-methylpyrrolidine (98\%, Acros organics, Geel, B) are dissolved in $70 \mathrm{ml}$ dry acetonitrile. $0.1 \mathrm{~mol}$ of the respective n-alkylbromide (n-decylbromide, $98 \%$ Acros organics, Geel, B; n-dodecylbromide, $99 \%$ Acros organics, Geel, B) were added drop wise and the reaction mixture was heated under reflux for $18 \mathrm{~h}$. After cooling to room temperature the solution is concentrated by removing partially the solvent under vacuum. Upon adding the concentrated acetonitrile solution drop wise to $300 \mathrm{ml}$ cold $\left(-30^{\circ} \mathrm{C}\right)$ dry toluene 
the $\mathrm{N}$-alkyl-N-methylpyrrolidinium bromide precipitates as a white powder. The reaction product is filtered off and re-crystallized two times from dry acetonitrile/toluene. The product is dried from any remaining solvent for $48 \mathrm{~h}$ under dynamic vacuum at $70^{\circ} \mathrm{C}$. Yield: $\sim 70 \%$

Single crystals for structure analysis of both compounds were grown at ambident temperature from acetonitrile solutions via isothermal evaporation of the solvent.

\section{$\left[\mathrm{C}_{10} \mathrm{mpyr}\right] \mathrm{Br}(1)$}

\section{${ }^{1} \mathrm{H}-\mathrm{NMR} \underline{\delta}_{\underline{\mathrm{H}}}\left(298 \mathrm{~K}, 250.1 \mathrm{MHz}, \mathrm{CDCl}_{\underline{3}}\right):$}

0.848 [t, 3H, H-8)]; 1.227 [s, 14H, H-7]; 1.740 [m, 2H, H-6]; 2.277 [m, 4H, H2/3]; 3.293 [s, 3H, H-9]; 3.633 [m, 2H, H-5]; 3.849 [m, 4H, H-1/H-4].

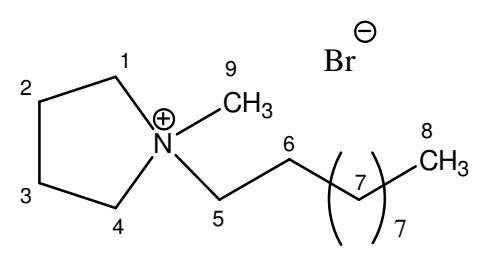

Scheme 1. Atom assignment in $\left[\mathrm{C}_{10} \mathrm{mpyr}\right] \mathrm{Br}(\mathbf{1})$.

MIR (KBr pellet): $\Xi /\left[\mathrm{cm}^{-1}\right]=2996.8(\mathrm{~m}), 2983.4(\mathrm{~m}), 2954.5(\mathrm{~s}), 2944.8(\mathrm{~s})$, $2919.7(\mathrm{~s}), \quad 2871.5(\mathrm{~m}), \quad 2850.3(\mathrm{~s}), \quad 1629.6(\mathrm{w}), \quad 1481.1(\mathrm{~m}, \quad$ shoulder$)$, $1473.4(\mathrm{~m}), \quad 1463.7(\mathrm{~m}), \quad 1436.7(\mathrm{~m}), \quad 1402.0(\mathrm{w}), \quad 1377.0(\mathrm{w}), \quad 1369.2(\mathrm{w}$, shoulder), $1342.2(\mathrm{vw}), 1330.7(\mathrm{vw}), 1317.2(\mathrm{vw}), 1299.9(\mathrm{vw}), 1263.2(\mathrm{vw})$, $1251.6(\mathrm{vw}), 1240.0(\mathrm{vw}), 1207.2(\mathrm{vw}), 1197.6(\mathrm{vw}), 1186.0(\mathrm{vw}), 1147.5(\mathrm{vw})$, $1126.2(\mathrm{vw}), 1095.4(\mathrm{vw}), 1083.8(\mathrm{vw}), 1047.2(\mathrm{w}), 1020.2(\mathrm{w}), 1008.6(\mathrm{w})$, $987.4(\mathrm{vw}), \quad 977.8(\mathrm{vw}), \quad 960.4(\mathrm{vw}), \quad 933.4(\mathrm{~m}), \quad 908.3(\mathrm{vw}), \quad 896.8(\mathrm{vw}$, 
shoulder), $883.3(\mathrm{vw}), 852.4(\mathrm{vw}), 829.3(\mathrm{w}), 798.4(\mathrm{w}), 759.8(\mathrm{vw}), 738.6(\mathrm{w}$, shoulder), $729.0(\mathrm{w}), 719.3(\mathrm{w}), 626.8(\mathrm{vw})$.

FIR (PE pellet): $\Xi /\left[\mathrm{cm}^{-1}\right]=477.3(\mathrm{w}), 442.6(\mathrm{w}), 414.6(\mathrm{w}), 375.1(\mathrm{w})$, $323.0(\mathrm{w}), 288.3(\mathrm{w}), 230.5(\mathrm{w}), 224.7(\mathrm{w}), 175.5(\mathrm{w}), 155.2(\mathrm{w}), 82.9(\mathrm{~m})$, $59.8(\mathrm{~m})$.

Raman: $\Xi /\left[\mathrm{cm}^{-1}\right]=2996.8(\mathrm{~s}), 2983.3(\mathrm{~s}), 2964.0(\mathrm{~s}), 2942.8(\mathrm{~s}), 2883.0(\mathrm{vs})$, $2856.0(\mathrm{~s}), \quad 2844.5(\mathrm{~s}), \quad 2788.5(\mathrm{w}), \quad 2719.1(\mathrm{w}), \quad 1457.9(\mathrm{~m}), \quad 1440.5(\mathrm{~m})$, $1427.0(\mathrm{~s}), \quad 1371.1(\mathrm{vw}), \quad 1319.0(\mathrm{w}), \quad 1295.9(\mathrm{~m}), \quad 1238.0(\mathrm{~s}), \quad 1126.2(\mathrm{~m})$, $1083.7(\mathrm{vw}), \quad 1062.5(\mathrm{~m}), \quad 1054.8(\mathrm{~m}), \quad 933.3(\mathrm{vw}), \quad 896.7(\mathrm{w}), \quad 883.2(\mathrm{w})$, $829.2(\mathrm{vw}), \quad 800.3(\mathrm{vw}), \quad 759.8(\mathrm{vw}), \quad 740.5(\mathrm{w}), \quad 734.7(\mathrm{w}), \quad 628.6(\mathrm{w})$, $511.0(\mathrm{vw}), 476.3(\mathrm{w}), 455.1(\mathrm{w}), 441.6(\mathrm{w}), 414.6(\mathrm{w}), 376.0(\mathrm{w}), 322.0(\mathrm{vw})$, $163.8(\mathrm{w})$.

Elemental analysis (\%) calcd for [ $\left.\mathrm{C}_{10} \mathrm{mpyr}\right] \mathrm{Br}$ : C 58.82, H 10.46, N 4.58; found: C 58.73, H 10.36, N 4.58.

\section{$\left[\mathrm{C}_{12} \mathrm{mpyr}\right] \mathrm{Br}(2)$}

${ }^{1} \mathrm{H}-\mathrm{NMR} \underline{\delta}_{\underline{H}}\left(298 \mathrm{~K}, 300 \mathrm{MHz}, \mathrm{DMSO}-\underline{\mathrm{d}}_{6}\right): 0.85$ (t; 3H; H-9), $1.26(\mathrm{~s} ; 18 \mathrm{H} ; \mathrm{H}-$ 8), 1.62-1.74 (m; 2H; H-7), 2.03-2.11 (m; 4H; H-3/H-4), 2.97 (s; 3H, H-10), 3.24-3.33 (m, 2H; H-6), 3.38-3.50 (m; 4H; H-2/H-5). 


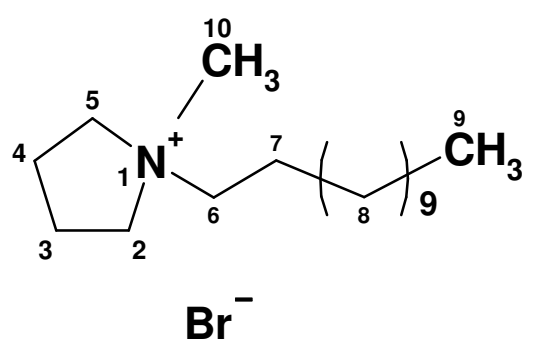

Scheme 2. Atom assignment in $\left[\mathrm{C}_{12} \mathrm{mpyr}\right] \mathrm{Br}(\mathbf{2})$.

MIR: (KBr pellet): $\Xi /\left[\mathrm{cm}^{-1}\right]=2998.7(\mathrm{~s}), 2983.7(\mathrm{~s}), 2953.5(\mathrm{~s}), 2945.3(\mathrm{~s})$, $2920.0(\mathrm{~s}), \quad 2872.0(\mathrm{~s}), \quad 2850.0(\mathrm{~s}), \quad 1472.7(\mathrm{~s}), \quad 1462.9(\mathrm{~s}), \quad 1436.5(\mathrm{~m})$, $1401.2(\mathrm{~m}), \quad 1374.8(\mathrm{~m}), \quad 1348.5(\mathrm{~m}), \quad 1331.1(\mathrm{~m}), 1303.3(\mathrm{~m}), \quad 1248.3(\mathrm{~m})$, $1193.4(\mathrm{w}), \quad 1148.9(\mathrm{w}), \quad 1128.6(\mathrm{w}), \quad 1098.5(\mathrm{w}), \quad 1044.3(\mathrm{~m}), \quad 1012.7(\mathrm{~m})$, $990.9(\mathrm{~m}), 962.2(\mathrm{~m}), 930.6(\mathrm{~s}), 893.0(\mathrm{w}), 841.0(\mathrm{w}), 827.5(\mathrm{~m}), 796.6(\mathrm{w})$, $762.7(\mathrm{~m}), 731.1(\mathrm{~s}), 719.8(\mathrm{~s}), 628.7(\mathrm{w})$

FIR (PE pellet): $\quad \Xi /\left[\mathrm{cm}^{-1}\right]=541.9(\mathrm{w}), 511.1(\mathrm{vw}), 500.5(\mathrm{vw}), 475.4(\mathrm{w})$, $462.9(\mathrm{w}), 443.6(\mathrm{w}), 418.5(\mathrm{w}), 376.1(\mathrm{w}), 353.9(\mathrm{w}), 284.5(\mathrm{w}), 148.5(\mathrm{~m})$, $132.1(\mathrm{~m}), 77.1(\mathrm{~s})$.

Raman: $\Xi /\left[\mathrm{cm}^{-1}\right]=2995.3(\mathrm{~m}), 2983.7(\mathrm{~s}), 2962.6(\mathrm{~s}), 2941.3(\mathrm{~s}), 2881.5(\mathrm{~s})$, 2846.8 (s), $2787.0(\mathrm{vw}), 2731.1(\mathrm{w}), 2721.5(\mathrm{w}), \quad 1460.1(\mathrm{w}), \quad 1442.7(\mathrm{w})$, $1420.4(\mathrm{w}), 1371.4(\mathrm{vw}), 1311.7(\mathrm{vw}), 1294.3(\mathrm{w}), 1232.6(\mathrm{vw}), 1126.5(\mathrm{w})$, $1089.9(\mathrm{vw}), \quad 1059.0(\mathrm{w}), 1010.8(\mathrm{vw}), 989.6(\mathrm{vw}), 931.7(\mathrm{vw}), \quad 897.0(\mathrm{w})$, $881.6(\mathrm{w}), \quad 740.8(\mathrm{vw}), \quad 731.1(\mathrm{vw}), \quad 625.1(\mathrm{vw}), \quad 443.8(\mathrm{vw}), \quad 414.9(\mathrm{vw})$, $376.3(\mathrm{vw}), 146.7(\mathrm{w}), 110.1(\mathrm{vw}), 83.1(\mathrm{vw})$.

Elemental analysis (\%) calcd for [ $\left.\mathrm{C}_{12} \mathrm{mpyr}\right] \mathrm{Br}$ : C 61.08, H 10.85, N 4.19; found: C 60.82, H 11.10, N 4.21.

For a graphical representation of the spectra see Supporting Information. 
Elemental Analysis. Elemental analyses were obtained on an elemental analyzer Vario EL (Elementar Analysensysteme $\mathrm{GmbH}$, Hanau, D) for $\left[\mathrm{C}_{10} \mathrm{mpyr}\right] \mathrm{Br}$ (1) and an Euro Vektor elemental analyzer EuroEA 3000 (HEKAtech $\mathrm{GmbH}$, Wegberg, D) for [ $\left.\mathrm{C}_{12} \mathrm{mpyr}\right] \mathrm{Br}(2)$.

${ }^{1}$ H-NMR. Nuclear magnetic resonance (NMR) spectra were recorded on a Bruker DPX 250b (operating at $250.1 \mathrm{MHz}$ for ${ }^{1} \mathrm{H}$ ) and a Bruker AC-300 spectrometer (operating at $300 \mathrm{MHz}$ for ${ }^{1} \mathrm{H}$ ) (Bruker Germany GmbH, D).for (1) and (2) respectively.

IR-Raman-Spectroscopy. IR spectra of the solid were recorded using a IFS66V-S Fourier Transform IR spectrometer (Bruker Optik GmbH, Ettlingen, D); samples were measured pressed in a polyethylene matrix for far IR range (50$600 \mathrm{~cm}^{-1}$ ) and in $\mathrm{KBr}$ matrix for middle IR (MIR) range $\left(600-4000 \mathrm{~cm}^{-1}\right)$. Raman spectra were recorded with a FRA 106-S Fourier Transform Raman spectrometer (Bruker Optik GmbH, Ettlingen, D) at 150mW. Raman samples were measured in glass capillaries with an inner diameter of $0.1 \mathrm{~cm}$ and 0.15 mm wall thickness.

Thermal measurements. Differential scanning calorimetry (DSC) was performed with a computer-controlled Phoenix DSC 204 F1 thermal analyser (Netzsch, Selb, D) with argon as protection gas. The samples were placed in aluminium pans which were cold-sealed under argon. Experimental data are displayed in such a way that exothermic peaks occur at negative heat flow and endothermic peaks at positive heat flow. DSC runs included heating up to 180 ${ }^{\circ} \mathrm{C}$ for (1) and $200^{\circ} \mathrm{C}$ for (2) at a rate of $5^{\circ} \mathrm{C} / \mathrm{min}$ and subsequent cooling to - 
$110^{\circ} \mathrm{C}$ at $5^{\circ} \mathrm{C} / \mathrm{min}$. Given temperatures correspond to the onset of the respective thermal process.

Polarizing Optical Microscopy. Optical analyses were carried out with an Axio Imager A1 microscope (Carl Zeiss MicroImaging GmbH, Göttingen, D) equipped with a hot stage, THMS600 (Linkam Scientific Instruments Ltd, Surrey, UK), and a Linkam TMS 94 (Linkam Scientific Instruments Ltd, Surrey, UK) temperature controller and crossed polarizers. Images were recorded at a magnification of $100 \times$ as movies with a digital camera after initial heating during the cooling stage. Heating and cooling rates were $5^{\circ} \mathrm{K} / \mathrm{min}^{-1}$. For the measurement the samples were placed under argon between two cover slips which were sealed with two-component adhesive (UHU plus 300, UHU GmbH \& Co. KG, Bühl, D).

Powder X-ray diffraction. Powder X-ray diffraction (XRD)data were obtained using an Image Plate Guinier Camera (Stoe Stadi P, Stoe, Darmstadt, D) diffractometer $\left(\mathrm{CuK}_{\alpha}\right)$.

The data confirm the results from X-ray structure analysis as well as the sample purity.

Crystal Structure Analysis. A few crystals of $\mathbf{1}$ and $\mathbf{2}$ were selected at ambient temperature with the help of an optical microscope. Suitable single crystals were sealed under inert conditions in Lindeman glass capillaries. All data were collected on a Stoe IPDS-II single-crystal X-ray diffractometer with graphite monochromated Mo $K_{\alpha}$ radiation $(\lambda=0.71073 \AA$ at 298(2) K). Crystal structure solution by direct methods using SIR $92^{9}$ yielded the heavy atom positions. Subsequent difference Fourier analyses and least squares refinement with SHELXL- $97^{10}$ allowed for the location of the remaining atom positions. In 
the final step of the crystal structure refinement hydrogen atoms of idealized $\mathrm{CH}_{2}$ and $-\mathrm{CH}_{3}$ groups were added and treated with the riding atom mode; their isotropic displacement factor was chosen as 1.2 times the preceding carbon atom. Data reduction was carried out with the program package X-Red ${ }^{11}$ and numerical absorption correction was carried out with the program X-Shape ${ }^{12}$ For further information see Supporting Information. CCDC-682995 and CCDC682996 contain the supplementary crystallographic data for $\mathbf{1}$ and $\mathbf{2}$. These data can be obtained free of charge from The Cambridge Crystallographic Data Centre via www.ccdc.cam.ac.uk/data_request/cif. For drawings of the crystal structure the program DiAMOND 3 was used. ${ }^{13}$

\section{Results and Discussion}

\section{Crystal Structures.}

Single Crystals of $\left[\mathrm{C}_{10} \mathrm{mpyr}\right] \mathrm{Br}(1)$ and $\left[\mathrm{C}_{12} \mathrm{mpyr}\right] \mathrm{Br}$ (2) were obtained by isothermal evaporation from acetonitrile solutions at ambient temperature. Both compounds form colourless, thin plate-like crystals. Single crystal X-ray structure analysis reveals that $\mathbf{1}$ and $\mathbf{2}$ both crystallize in the monoclinic space group $P 2_{1} / n$ (no. 4) (1: $a=19.446(2) \AA, b=7.0659(5) \AA, c=36.844(4) \AA, \beta=$ 90.63(1) $)^{\circ}, \mathrm{V}=5062.2(8) \AA^{3} ; 2: a=20.457(8) \AA, b=7.0796(16) \AA, c=$ 39.335(14) $\AA, \beta=96.96(3)^{\circ}, \mathrm{V}=5655(3) \AA^{3}$ ) with 12 formula units in the unit cell (Table 1). Both compounds crystallize not isotypic but isostructural. ${ }^{14}$ Of the 12 formula units present in the unit cell three are crystallographically independent. Bonding distances and angles for the N-n-alkyl-Nmethylpyrrolidinium cation in $\mathbf{1}$ and $\mathbf{2}$ are well in the expected range and can be compared to the ones found for e.g. N-butyl-N-methylimidazolium compounds investigated by us previously. ${ }^{15}$ Every n-alkyl chain adopts all-trans 
conformations (Fig. 1) and the bonding distances and angles can be compared to the ones found for example in the crystalline 1-dodecyl-3-methylimidazolium bromide monohydrate, $\left[\mathrm{C}_{12} \mathrm{mim}\right] \mathrm{Br} \bullet \mathrm{H}_{2} \mathrm{O} .{ }^{16}$ The well ordered nature of the long alkyl side chains in both crystal structures may be forced by the crystal packing as the chains intertwined. The $\mathrm{N}$-alkyl-N-methyl-pyrrolidinium cations form sheet-like double layers in the $a, c$ plane which run along the unique axis $b$. The cations stack along the unique axis $b$ in such a way that their alkyl tails alternate in orientation in the neighbouring layers. The alkyl tails of the cation are tilted with an angle of $41.5^{\circ}$ for $\mathbf{1}$ and $48.5^{\circ}$ for 2 with respect to the bilayer normal. The bilayer thickness is $15.0364 \pm 0.0055 \AA$ for $\mathbf{1}$ and $16.8072 \pm 0.0063 \AA$ for 2 .

Table 1. Crystal parameters for $\mathbf{1}$ and $\mathbf{2}$.

\begin{tabular}{|l|l|l|}
\hline & $\mathbf{1}$ & $\mathbf{2}$ \\
\hline Formula & $\mathrm{C}_{15} \mathrm{H}_{32} \mathrm{~N} \mathrm{Br}$ & $\mathrm{C}_{17} \mathrm{H}_{36} \mathrm{~N} \mathrm{Br}$ \\
\hline Formula weight / $\bullet \mathrm{mol}^{-1}$ & 306.33 & 334.38 \\
\hline Crystal system & Monoclinic & Monoclinic \\
\hline Space group & $P 2_{1} / n$ (no. 14) & $P 2_{1} / n$ (no. 14) \\
\hline$a / \AA$ & $19.446(2)$ & $20.457(8)$ \\
\hline$b / \AA$ & $7.0659(5)$ & $7.0796(16)$ \\
\hline$c / \AA$ & $36.844(4)$ & $39.335(14)$ \\
\hline$\beta /{ }^{\circ}$ & $90.629(8)$ & $96.96(3)$ \\
\hline $\mathrm{V} / \AA^{3}$ & $5062.1(8)$ & $5655(3)$ \\
\hline $\mathrm{Z}$ & 12 & 12 \\
\hline$\rho /\left(\mathrm{g} \bullet \mathrm{cm}^{-3}\right)$ & 1.206 & 1.178 \\
\hline$\mu / \mathrm{mm}^{-1}$ & 2.421 & 2.173 \\
\hline $\mathrm{R}_{\text {INT }}$ & 0.0654 & 0.1147 \\
\hline No. reflections measured & 48994 & 43019 \\
\hline Unique data & 4317 & 4019 \\
\hline
\end{tabular}




\begin{tabular}{|l|l|l|}
\hline Observed data & 8958 & 9739 \\
\hline No. of parameters & 465 & 519 \\
\hline $\mathrm{R}, \mathrm{R}_{\mathrm{w}}$ & $0.0372,0.0822$ & $0.0431,0.0753$ \\
\hline GooF & 0.897 & 0.823 \\
\hline
\end{tabular}

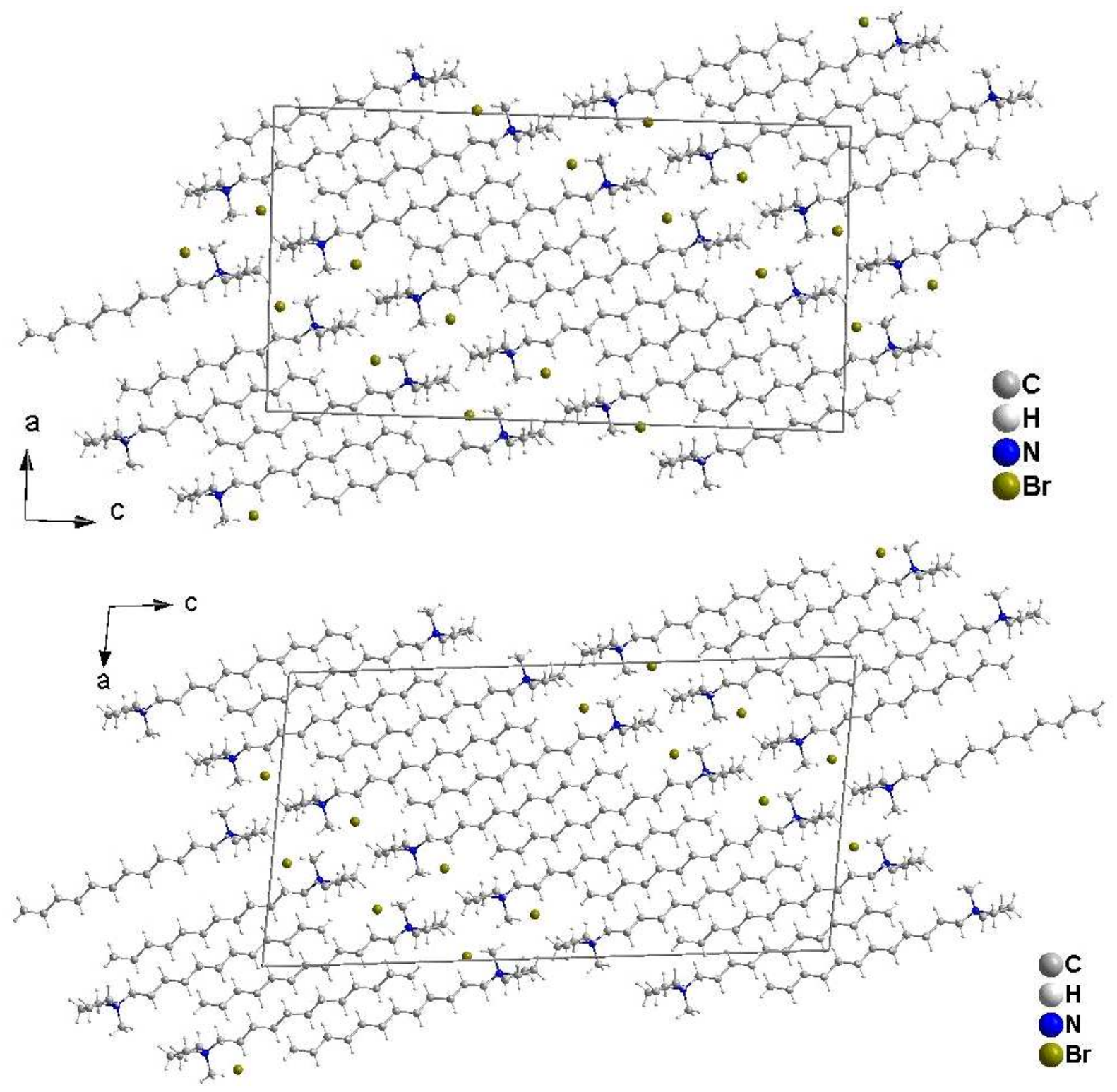

Figure 1. $\left[\mathrm{C}_{10} \operatorname{mpyr}\right] \mathrm{Br}(\mathbf{1}$, top $)$ and $\left[\mathrm{C}_{12} \operatorname{mpyr}\right] \mathrm{Br}(\mathbf{2}$, bottom), view of the crystal structure along the crystallographic unique $b$ axis. 

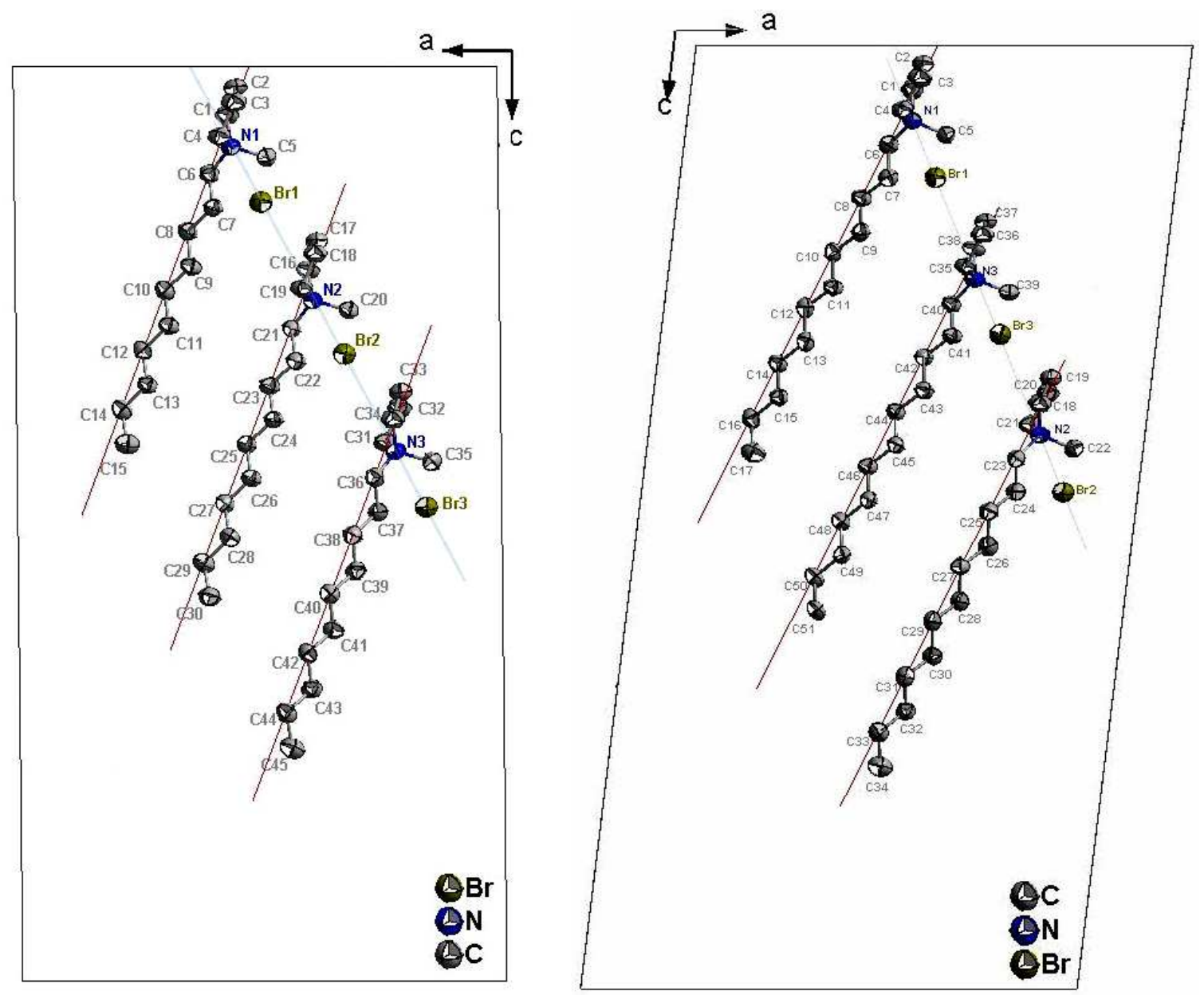

Figure 2. Asymmetric units of the crystal structure of $\left[\mathrm{C}_{10} \mathrm{mpyr}\right] \mathrm{Br}(1$, left $)$ and . $\left[\mathrm{C}_{12} \mathrm{mpyr}\right] \mathrm{Br}(2$, right). ( $\mathrm{H}$ atoms are omitted for clarity reasons.)

Within the double layers a structural segregation into hydrophilic and hydrophobic domains can be observed. The hydrophobic parts are formed by the interdigitated n-alkyl chains of the pyrrolidinium cation whereas the charged pyrrolidinium head groups together with the bromide anions form the hydrophilic structure part. Each pyrrolidinium head group is surrounded by a rectangular pyramid of bromide anions. The charge bearing nitrogen atoms of the pyrrolidinium cation lie exactly in the basis of this pyramid. The rectangular bromide pyramids are connected via trans-edges within the layers (Fig. 3). However, four distances to the bromide anions are distinctly shorter than the last one so that the coordination number of the cation is rather four. Vice versa the bromide ions are surrounded by a distorted tetrahedron formed by the 
pyrrolidinium head groups. Non-classical hydrogen bonds between cations and anions can be discussed, although the mean $\mathrm{Br}^{\cdots} \mathrm{H}$, or better, the mean $\mathrm{Br}^{\cdots \cdots} \mathrm{C}_{\mathrm{H}}$ distances, as the hydrogen atoms positions were calculated during structure refinement, are slightly larger than the typical values of 2.7 and $3.7 \AA{ }^{17}$
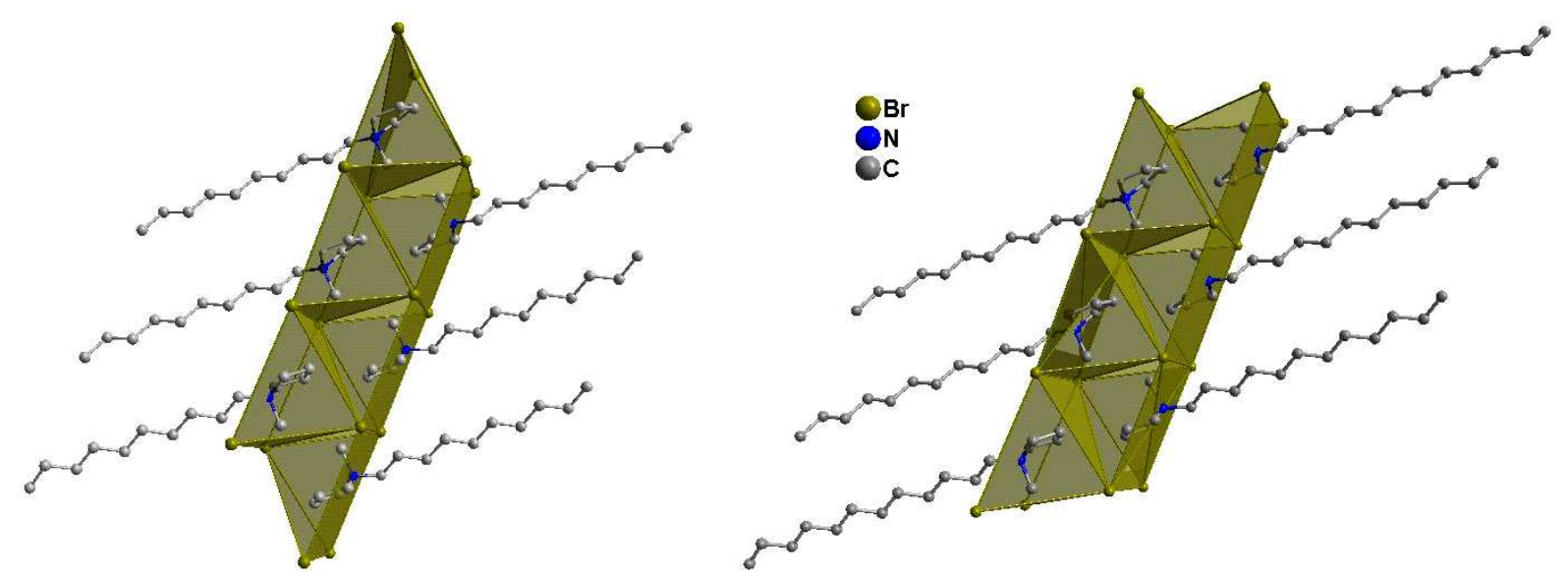

Figure 3. Local surrounding of the pyrrolidinium head groups by bromide in $\left[\mathrm{C}_{10} \operatorname{mpyr}\right] \mathrm{Br}(\mathbf{1}$, left $)$ and $\left[\mathrm{C}_{12} \mathrm{mpyr}\right] \mathrm{Br}(\mathbf{2}$, right). ( $\mathrm{H}$ atomes are omitted for clarity reasons.)

\section{Thermal Analysis.}

The thermal properties of $\mathbf{1}$ and $\mathbf{2}$ were examined by polarizing optical microscopy (POM) as well as differential scanning calorimetry (DSC). The DSC traces of $\mathbf{1}$ and $\mathbf{2}$ are shown in Figures 4 and 6, transition temperatures and assignments for phase transitions (as confirmed by POM) are given in Table 2 and 3. Although $\mathbf{1}$ and $\mathbf{2}$ crystallize similarly their thermal behaviour deviates significantly.

The first heating cycle for crystalline $\mathbf{1}$ shows three exothermic peaks. The first observed thermal effect at $45.7^{\circ} \mathrm{C}$ marks the crystalline solid-liquid crystal (S-LC I) transition. The second effect at $89.2{ }^{\circ} \mathrm{C}$ is rather weak and corresponds to a transition between two liquid crystalline phases (LC I - LC II). The last exothermic effect at $164.8^{\circ} \mathrm{C}$ corresponds to the clearing point ( $\mathrm{LC} \mathrm{II}-\mathrm{L}_{\text {iso }}$ ). 
Upon cooling, the liquid - liquid crystalline transition is split into two distinct signals at $147.3{ }^{\circ} \mathrm{C}$ and $153.1{ }^{\circ} \mathrm{C}$ revealing an additional liquid crystal-liquid crystal transiton (LC III - LCII). Their combined enthalpy contributions amount roughly to the same value as observed for the effect found in the similar temperature regime upon heating. It is anticipated that the LC III - LC II transition takes also place upon heating. However, the thermal effects could not be resolved. In the cooling cycle the LC I - LC II takes place with a hysteresis of about $20{ }^{\circ} \mathrm{C}$. Upon further cooling no crystallization process can be observed, instead a glass transition takes place at $-80^{\circ} \mathrm{C}$. In the second heating cycle three thermal effects can be detected. At about $-90^{\circ} \mathrm{C}$ the melting (glass transition) of the material to the LC I phase is observed, at about $50^{\circ} \mathrm{C}$ the enantiotropic LC I - LC II transition and finally the melting to an isotropic liquid at $162.8^{\circ} \mathrm{C}$.

Table 2. Transition temperatures and enthalpies for $\left[\mathrm{C}_{10} \mathrm{mpyr}\right] \mathrm{Br}(1)$.

\begin{tabular}{|c|c|c|c|c|c|c|}
\hline 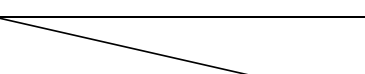 & \multicolumn{2}{|c|}{$1^{\text {st }}$ heating cycle } & \multicolumn{2}{|c|}{$1^{\text {st }}$ cooling cycle } & \multicolumn{2}{|c|}{$2^{\text {nd }}$ heating cycle } \\
\hline & $\mathbf{T} /{ }^{\circ} \mathbf{C}$ & $\Delta \mathrm{H} /(\mathrm{kJ} / \mathrm{mol})$ & $\mathrm{T} /{ }^{\circ} \mathbf{C}$ & $\Delta \mathrm{H} /(\mathrm{kJ} / \mathrm{mol})$ & $\mathbf{T} /{ }^{\circ} \mathbf{C}$ & $\Delta \mathrm{H} /(\mathrm{kJ} / \mathrm{mol})$ \\
\hline $\mathrm{S} \Leftrightarrow \mathrm{LC} I$ & 45.7 & 37.6 & $\sim-80$ & --- & $\sim-90$ & --- \\
\hline LC I $\Leftrightarrow$ LC II & $\sim 89$ & $\sim 0.62$ & $\sim 69.5$ & $\sim-0.65$ & $\sim 50$ & $\sim 0.4$ \\
\hline LC II $\Leftrightarrow$ LC III & --- & --- & 147.3 & \multirow{2}{*}{-8.1} & --- & --- \\
\hline LC II / III $\Leftrightarrow \mathrm{L}_{\text {iso }}$ & 164.8 & 8.8 & 153.1 & & 162.8 & 8.6 \\
\hline
\end{tabular}




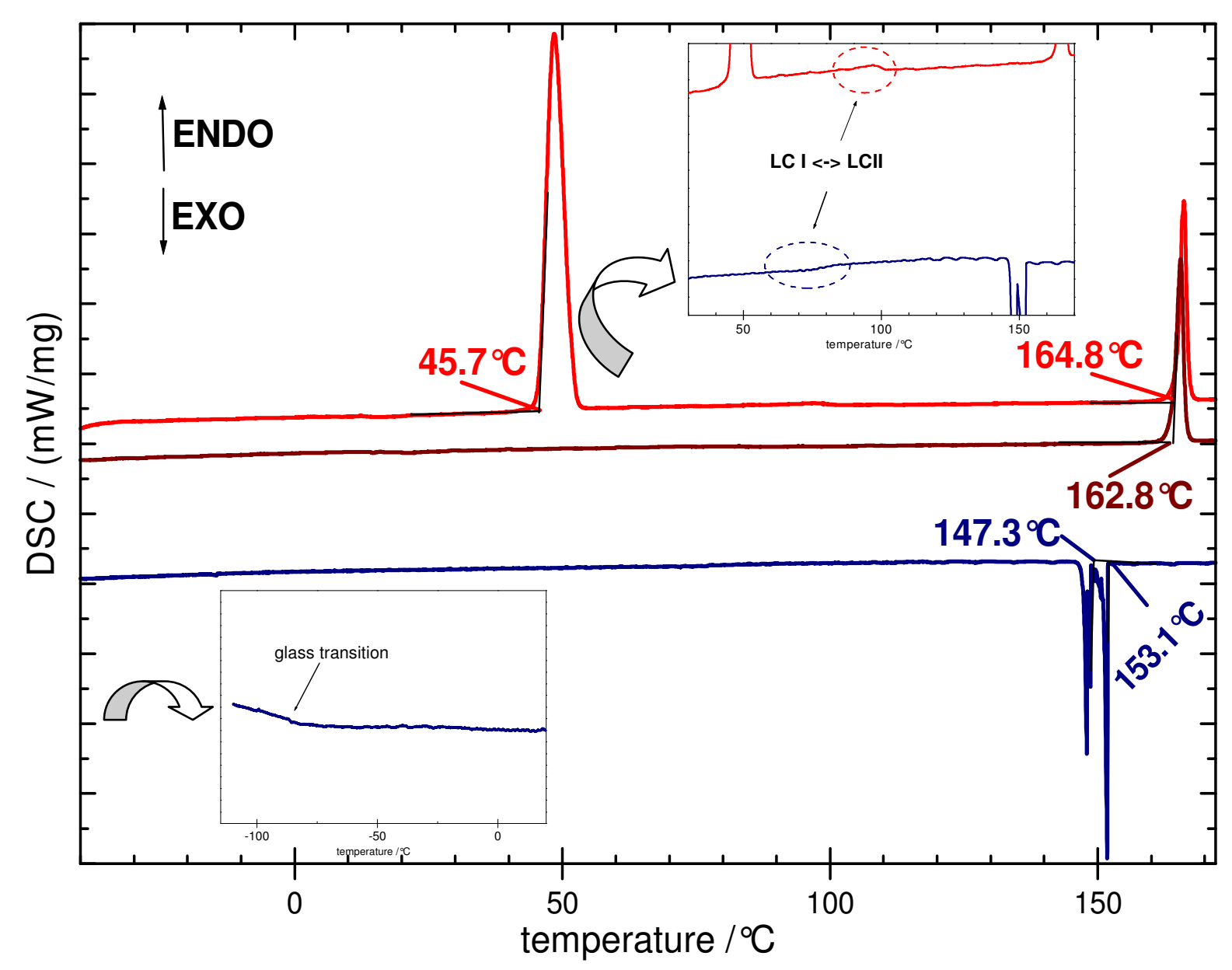

Figure 4. DSC thermogram for $\left[\mathrm{C}_{10} \mathrm{mpyr}\right] \mathrm{Br}(1)$, in red $1^{\text {st }}$ heating to $170^{\circ} \mathrm{C}$, in blue $1^{\text {st }}$ cooling, in brown $2^{\text {nd }}$ heating cycle.

It is quite difficult to observe good defect textures for ILCs by polarizing optical microscopy as the compounds show a strong tendency to form spontaneously homeotropic domains. ${ }^{18,19}$ In addition both compounds are strongly hygroscopic which puts restrains on sample handling during POM measurements (disturbing once formed homeotropic domains by applying external stress). Nevertheless, polarized optical micrographs (Fig. 5) could be obtained upon cooling from the isotropic liquid. The textures can be interpreted as smectic ones. Taking into account the single crystal X-ray structure LC II/LC III feature possibly a bilayered structure such as a $\mathrm{SmA}_{2}$ phase. The quite large enthalpy change could be indicative of a hexagonal or the rare tetragonal 
structure variant, the SmT phase. The LC II-LC I transition at lower temperatures possibly involves a tilting of the pyrrolidinium alkyltains with respect to the layer normal.

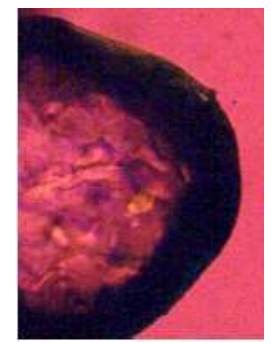

LC III

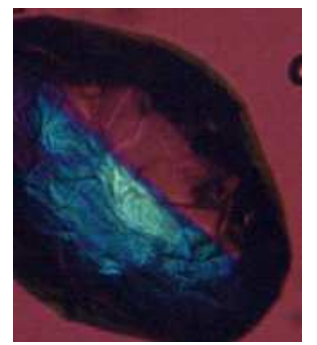

LC III $\rightarrow$ LC II

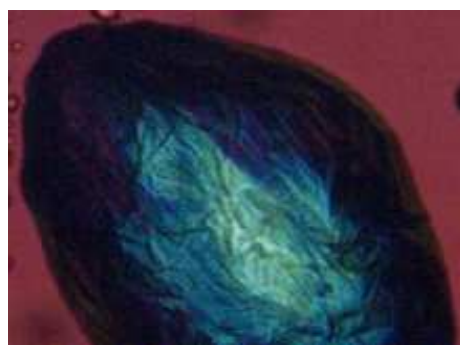

LC II

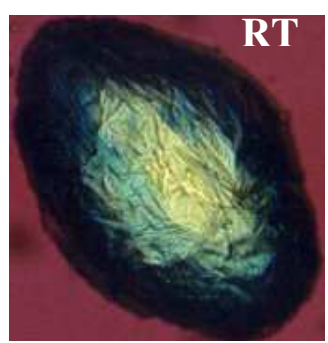

LC I

Figure 5. $\mathrm{POM}$ photos of $\left[\mathrm{C}_{10} \mathrm{mpyr}\right] \mathrm{Br}(\mathbf{1})$ at the respective temperatures upon cooling from the isotropic liquid.

Upon heating 2 the respective thermogram (Fig. 6) shows three exothermic events at $55.7^{\circ} \mathrm{C}, 83.4{ }^{\circ} \mathrm{C}$ and $192.3{ }^{\circ} \mathrm{C}$, respectively. The first signal corresponds to the melting of $\mathbf{2}$ to a liquid crystalline phase (LC I), whilst the second signal indicates a LC I-LC II transition. The last thermal event can be assigned to the clearing point ( $\mathrm{LC} \mathrm{II}-\mathrm{L}_{\text {iso }}$ ). All transitions occur reversibly as the cooling cycle shows, however, as can be seen from Table 2 with substantial hysteresis.

Table 3. Transition temperatures and enthalpies for $\left[\mathrm{C}_{12} \mathrm{mpyr}\right] \mathrm{Br}(\mathbf{2})$.

\begin{tabular}{|l|c|c|c|c|c|c|}
\hline & \multicolumn{2}{|c|}{$\mathbf{1}^{\text {st }}$ heating } & \multicolumn{2}{|c|}{$1^{\text {st }}$ cooling } & \multicolumn{2}{|c|}{$2^{\text {nd }}$ heating } \\
\hline & $\mathbf{T} /{ }^{\circ} \mathbf{C}$ & $\Delta \mathbf{H} /(\mathbf{k J} / \mathbf{m o l})$ & $\mathbf{T} /{ }^{\circ} \mathbf{C}$ & $\Delta \mathbf{H} /(\mathbf{k J} / \mathbf{m o l})$ & $\mathbf{T} /{ }^{\circ} \mathbf{C}$ & $\Delta \mathbf{H} /(\mathbf{k J} / \mathbf{m o l})$ \\
\hline $\mathbf{S} \Leftrightarrow \mathbf{L C}-\mathbf{I}$ & 55.7 & 45.7 & 26.6 & -13.6 & 25.1 & 14.4 \\
\hline $\mathbf{L C}-\mathbf{I} \Leftrightarrow \mathbf{L C}-\mathbf{I I}$ & 83.4 & 1.32 & 70.1 & -0.9 & 65.7 & 1.0 \\
\hline $\mathbf{L C}-\mathbf{I I} \Leftrightarrow \mathbf{L}_{\text {iso }}$ & 192.3 & $\sim 8.5$ & 183.7 & -6.9 & 179.0 & 6.7 \\
\hline
\end{tabular}




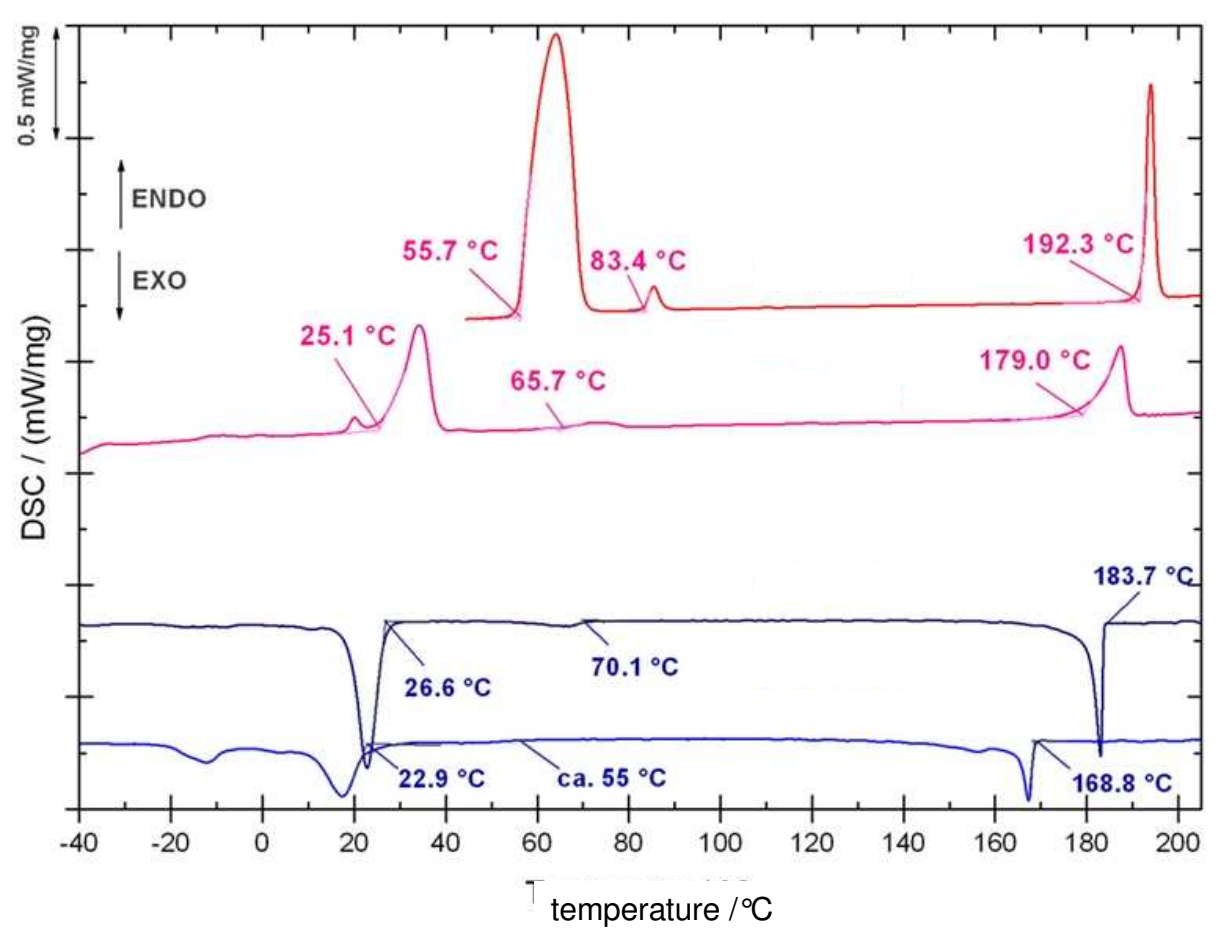

Figure 6. DSC thermogram for $\left[\mathrm{C}_{12} \operatorname{mpyr}\right] \mathrm{Br}(2)$, in dark red $1^{\text {st }}$, in dark blue $1^{\text {st }}$ cooling, in magenta $2^{\text {nd }}$ heating, in blue $2^{\text {nd }}$ cooling.

Polarized optical micrographs (Fig. 7, bottom) obtained upon first cooling of 2 from the isotropic liquid show a mosaic texture strongly reminding of a hexagonal smectic phase. The dark homeotropic areas point to an orthogonal phase. Upon further cooling the homeotropic areas lighten up which could originate from a tilting of the alkyl cations. The viscosity of the low temperature LC-I phase is substantially higher compared to the LC-II phase. This is indicative of a highly ordered smectic phase which might even be no longer a fluidic liquid-crystalline phases (e.g. SmC) but a hexatic liquid-crystalline phase such as SmI or SmF or even a soft crystalline state. ${ }^{20}$ 


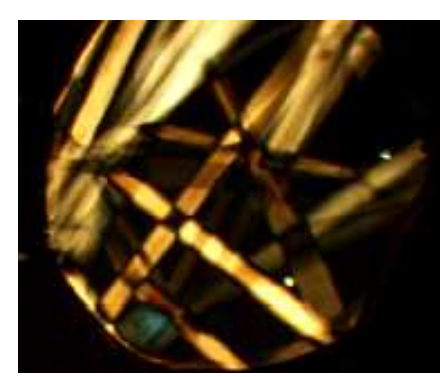

LC II

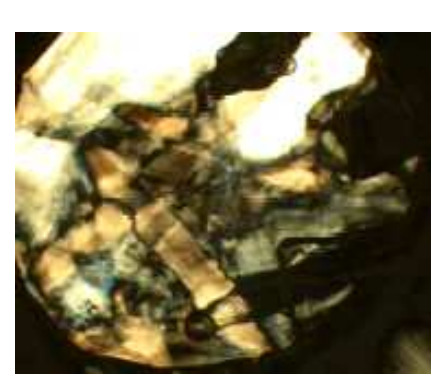

LC I

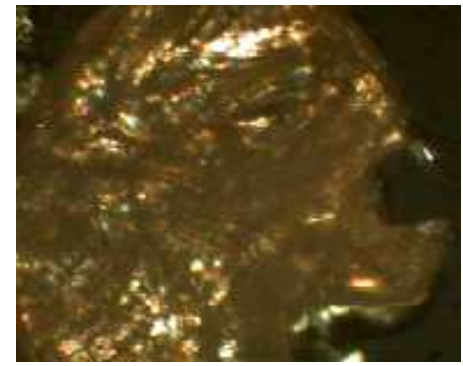

Solid

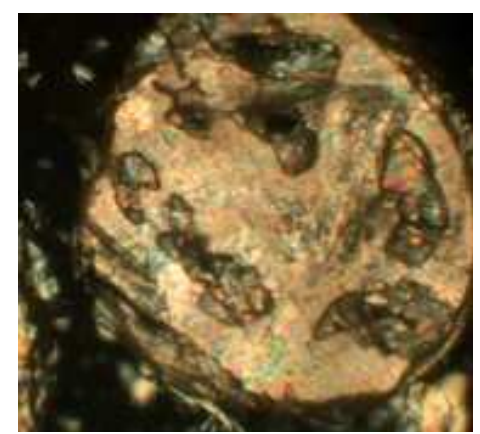

LC I

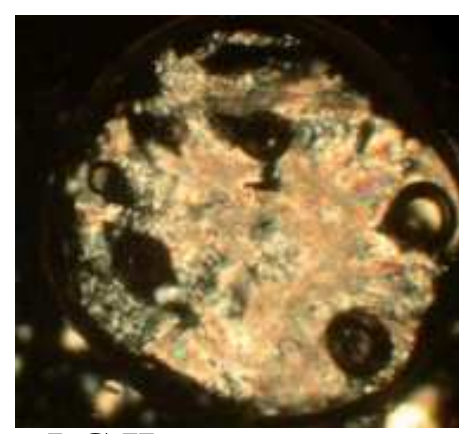

LC II

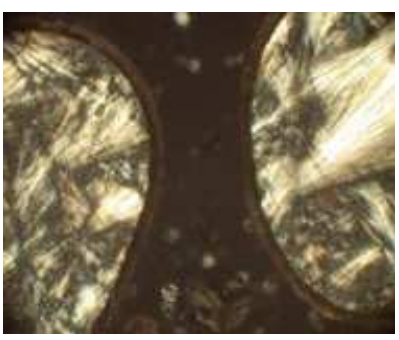

LC II

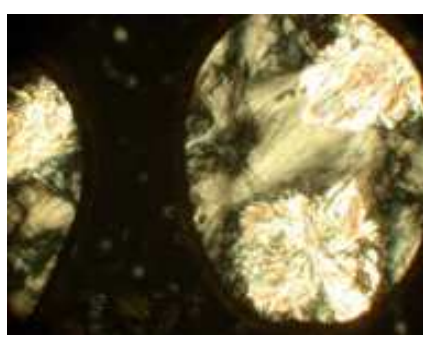

$\mathrm{LC}$ II $\rightarrow$ LC I

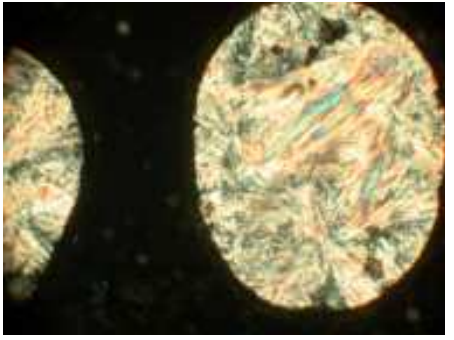

LC I

Figure 8. $\mathrm{POM}$ photos of $\left[\mathrm{C}_{12} \mathrm{mpyr}\right] \mathrm{Br}$ at the respective temperatures (see Table 3). Top row: $1^{\text {st }}$ cooling cycle (after heating up to isotropic liquid state); middle row: $2^{\text {nd }}$ heating cycle (same sample area); bottom row: $2^{\text {nd }}$ cooling cycle (textures are less clear). 


\section{Conclusions.}

The thermotropic liquid crystals $\left[\mathrm{C}_{10} \mathrm{mpyr}\right] \mathrm{Br}$ and $\left[\mathrm{C}_{12} \mathrm{mpyr}\right] \mathrm{Br}$ exhibit smectic mesophases over an appreciably high temperature range. Taking into account that practical applications of ILCs are often limited by the high melting points of the systems studied both compounds showing a high potential for further development. It is especially noteworthy that for $\left[\mathrm{C}_{10} \mathrm{mpyr}\right] \mathrm{Br}$ mesophase formation could be observed since, similar imidazolium compounds need at least a $\mathrm{C} 12$ side chain to form a liquid crystalline phase. ${ }^{21}$ All mesophases observed most probably are smectic phases with a strong tendency for spontaneous alignment in one direction. This feature may be interesting for some optical and electrical device applications. The single crystal X-ray structures obtained for both compounds represent the most stable packing of cations and anions. Already three independent formula units are present in the unit cell which shows that not all cations and anions are similar. The structural degree of freedom is raised in the liquid crystalline states. However, one has to be careful when directly correlating the single crystal structures to the mesophase ordering, as for example as a tilting of the molecules with respect to the layer normal in the crystalline state a does not necessarily lead to a tilted smectic phase. ${ }^{22}$ Nevertheless, both compounds adopt more than one layered mesophase. The strongly anisotropic nature of these ILCs could be used for the development of new functional materials that for example transport ions and electrons (as noted for smectic mesophases before). ${ }^{23}$

\section{Supporting Information Available.}

Supporting information include graphical representation of the vibrational spectra (MIR, FIR and Raman) of compounds $\mathbf{1}$ and 2, as well as the respective XRD powder patterns. 


\title{
Acknowledgements
}

This work was supported with in the framework of the DFG priority program SPP 1191 "Ionic Liquids". A.G. and A.-V. M. thank the Fonds der Chemischen Industrie for a Doktoranden- and Dozentenstipendium. Ingrid Müller and Dr. Ingo Pantenburg are acknowledged for data collection on the single crystal Xray diffractometer.

\section{Supporting Information}

\author{
Vibrational Spectroscopy
}

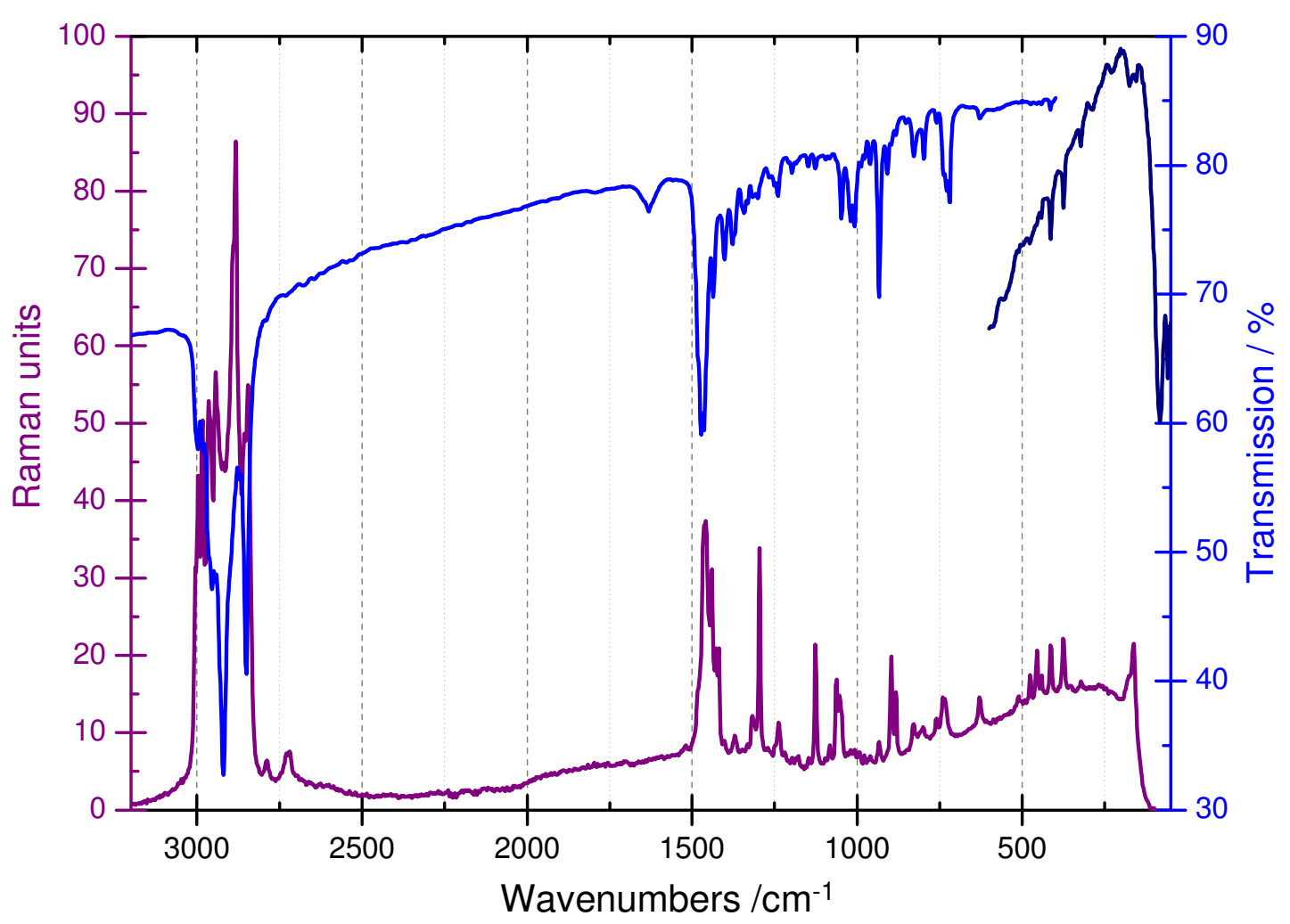


SI-Figure 1. Vibrational spectra of $\left[\mathrm{C}_{10} \mathrm{mpyr}\right] \mathrm{Br}$ (MIR spectrum in light blue; FIR spectrum in dark blue; Raman spectrum in violet).

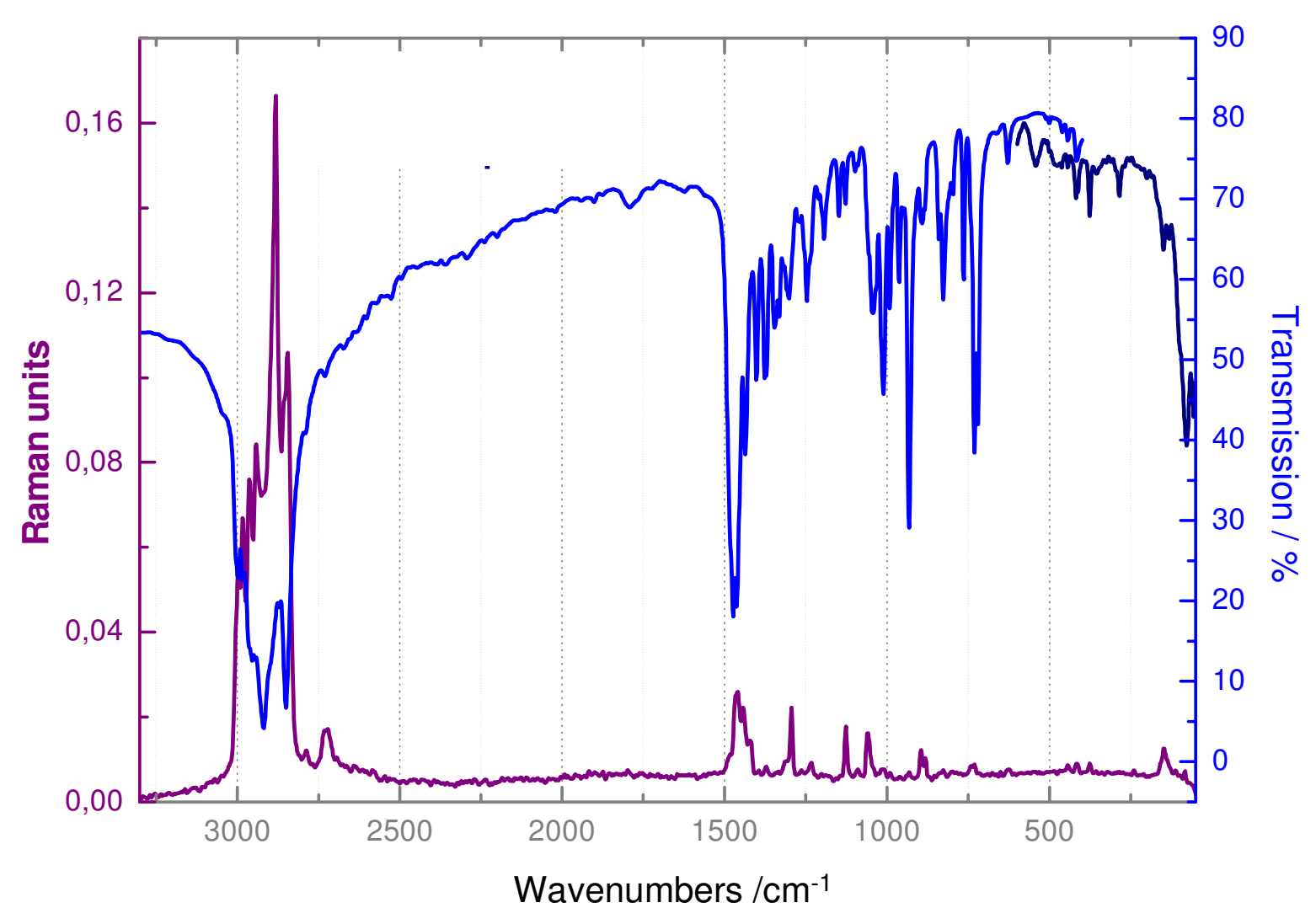

SI-Figure 2. Vibrational Spectra of $\left[\mathrm{C}_{12} \mathrm{mypr}\right] \mathrm{Br}$ (MIR spectrum in light blue; FIR spectrum in dark blue; Raman spectrum in violet). 


\section{Structural Information}

\section{Powder XRD}

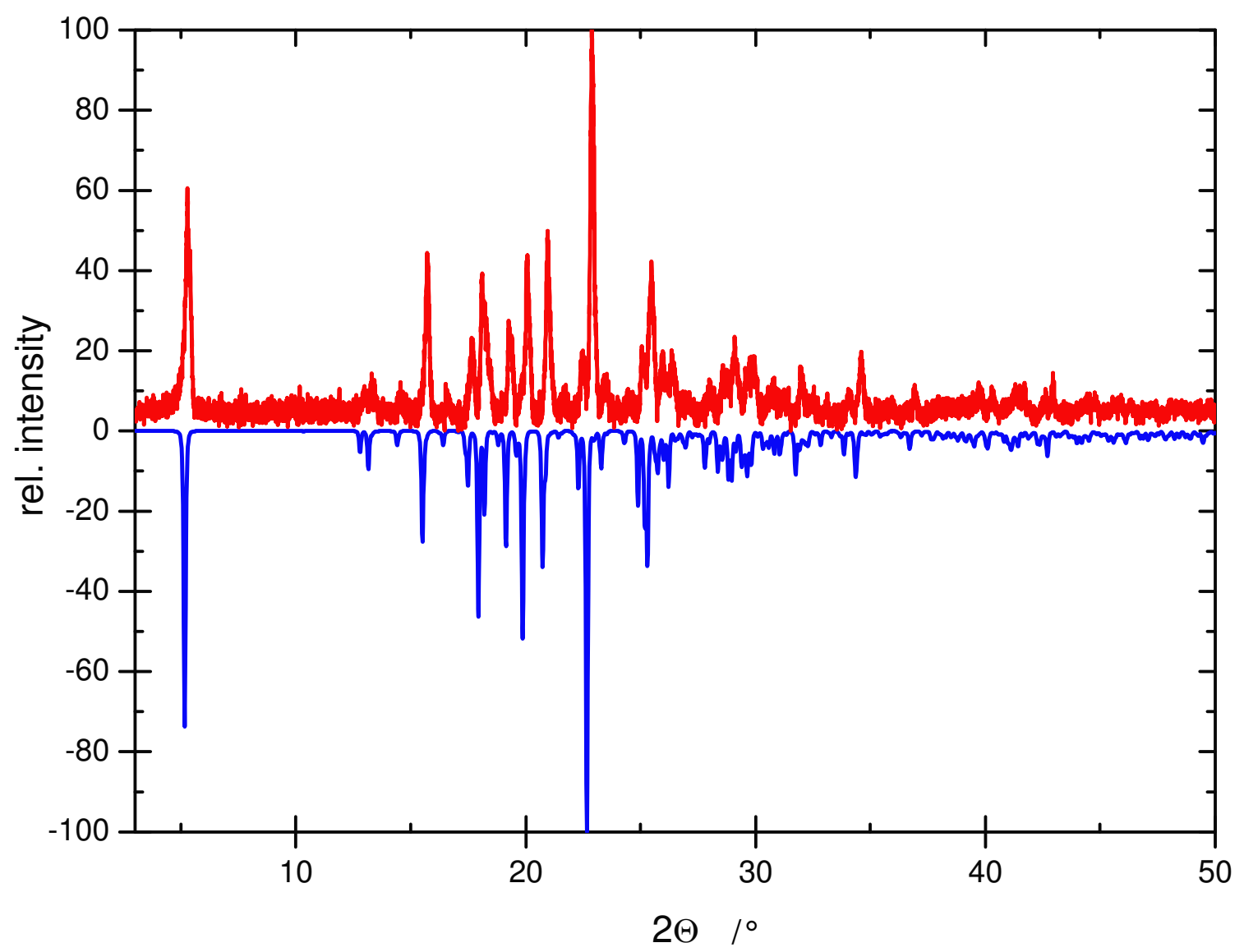

SI-Figure 3. Powder diffractogram of $\left[\mathrm{C}_{10} \mathrm{mypr}\right] \mathrm{Br}$ (measured diffractogram in red, from single X-ray data simulated diffractogram in blue). 


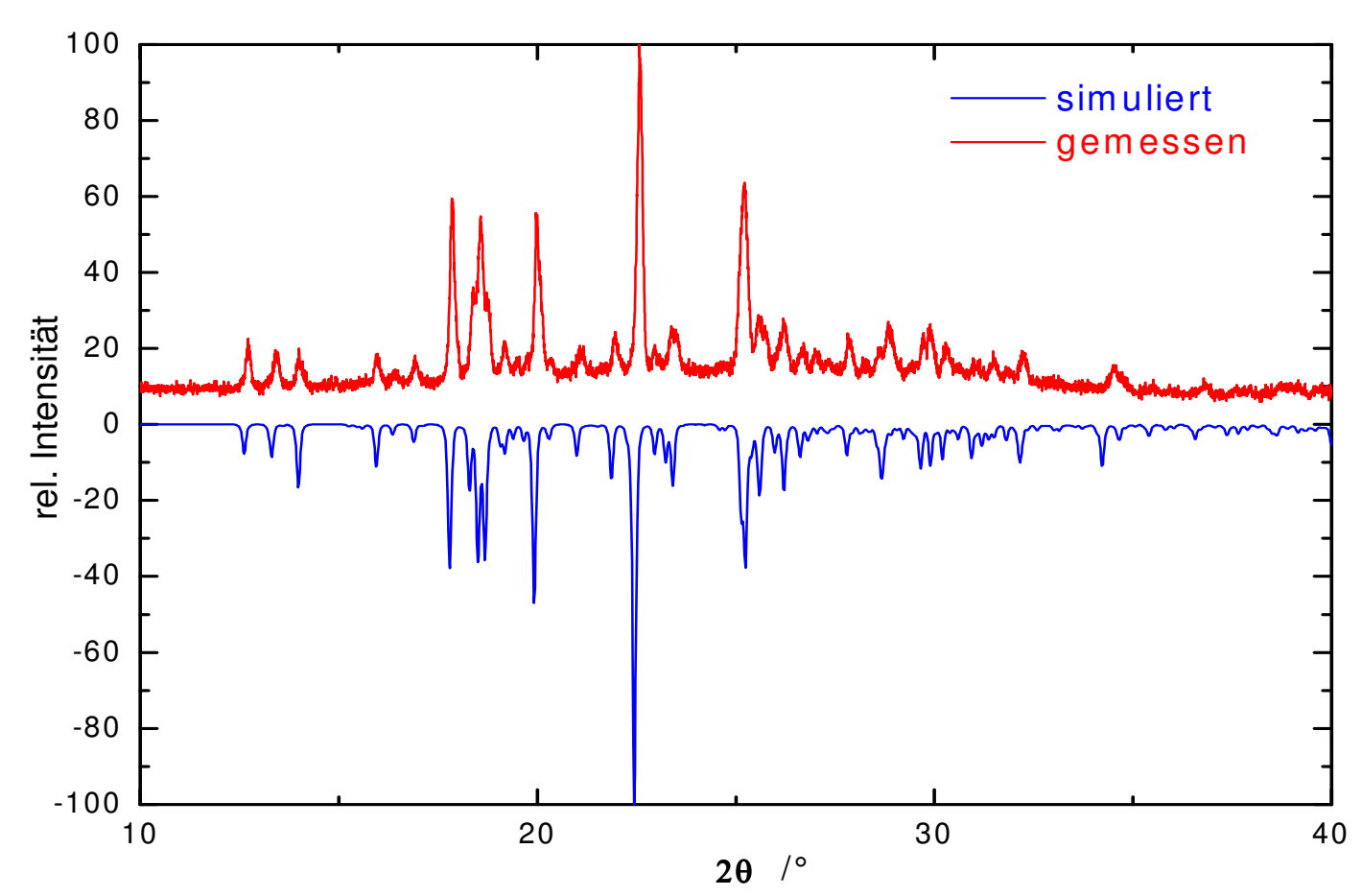

SI-Figure 4. Powder diffractogram of $\left[\mathrm{C}_{12} \mathrm{mypr}\right] \mathrm{Br}$ (measured diffractogram in red, from single X-ray data simulated diffractogram in blue).

\section{References}

${ }^{1}$ P.J. Collings, M. Hird, M., Introduction to Liquid Crystals: Chemistry and Physics, Taylor \& Francis, Ltd., 1997.

${ }^{2}$ F.D. Saeva, Liquid Crystals: The Fourth State of Matter; Marcel Dekker: New York, 1979.

${ }^{3}$ P.J. Collings, Liquid Crystals: Nature's Delicate Phase of Matter, Princeton University Press, 2002.

${ }^{4}$ C.M. Gordon, J.D. Holbrey, A.R. Kennedy, K.R.Seddon,; J. Mater. Chem. 1998, 8, 2627. 
${ }^{5}$ S.Ujiie, K. Iimura, Macromolecules 1992, 25, 3174.

${ }^{6}$ E. Alami, H. Levy, R. Zana, P. Weber, A. S koulios, Liq. Cryst. 1993, 13, 201.

${ }^{7}$ For an overview see: K. Binnemans, Chem. Rev. 2005, 105, 4148.

${ }^{8}$ K.K. Karukstis, J.R. McDonough, Langmuir 2005, 21, 5716.

${ }^{9}$ SIR92 - A program for crystal structure solution. A. Altomare, G. Cascarano,

C. Giacovazzo, A. Guagliardi, A. J. Appl. Crystallogr. 1993, 26, 343.

${ }^{10}$ SHELXL-97, W.S. Sheldrick, Universität Göttingen, 1997.

${ }^{11}$ X-RED; Stoe \& Cie: Darmstadt, 2002.

${ }^{12}$ X-Shape; Stoe \& Cie: Darmstadt, 2002.

${ }^{13}$ DIAMOND 3.0, Crystal Impact, Bonn, 2004.

${ }^{14}$ U. Müller, Anorganische Strukturchemie, Teubner Verlag, Stuttgart, 1991.

${ }^{15}$ A. Babai, A.-V. Mudring, Acta Crystallogr., 2005, E61, o2913; A. Babai, A.V. Mudring, Chem. Mat. 2005, 17, 6230; A. Babai, A.-V. Mudring, Inorg. Chem. 2006, 45, 3249; A. Babai, A.-V. Mudring, Dalton Trans., 2006, 1828; A. Babai, A.-V. Mudring, J. Alloys and Compounds, 2006, 418, 122; A. Babai, A.V. Mudring, Z. Anorg. Allg. Chem. 2006, 632, 1956; A. Babai, A.-V. Mudring, Inorg. Chem. 2006, 25, 4874.

${ }^{16}$ A. Getsis, A.-V. Mudring, Acta Crystallogr. 2005, E61, o2945

${ }^{17}$ T. Steiner, Acta Cryst. 1998, B54, 456.

${ }^{18}$ K. Binnemans, Chem. Rev. 2005, 105, 4148.

${ }^{19}$ W. Dobbs, L. Douce, L. Allouche, A. Louati, F. Malboscd, R. Weltere, , New J. Chem. 2006, 30, 528.

${ }^{20} \mathrm{~J}$. Goodby, Guide to the Nomenclature and Classification of Liquid Crystals. In D. Demus, J. Goodby, G. W. Gray, H.-W. Spies, V. Vill, , Eds.; Handbook of Liquid Crystals; Wiley-VCH, Weinheim, 1998; vol. 1, ch. II, p 17. 
${ }^{21}$ C.M. Gordon J.D. Holbrey, A.R. Kennedy, K.R. Seddon, J. Mat. Chem. 1998, 8, 2627.

${ }^{22}$ W. Haase, M.A. Athanassopoulou, Crystal Structures of LC Mesogenes in D.M.P Mingos (Ed), Liquid Crystals I, Springer, Berlin, 1999.

${ }^{23}$ M. Yoshio, T. Kagata, K. Hoshino, T. Mukai, H. Ohno, T. Kato, J. Am. Chem. Soc. 2006, 128, 5570; B.-K. Cho, A. Jain, S. M. Gruner, U. Wiesner, Science, 2004, 305, 1598; Y. Suzuki, N. Mizoshita, K. Hanabusa, T. Kato, J. Mater. Chem. 2003, 13, 2870. 